\title{
Cone-beam Effect Artifact
}

National Cancer Institute

\section{Source}

National Cancer Institute. Cone-beam Effect Artifact. NCI Thesaurus. Code C87012.

An artifact that occurs as the number of sections acquired per rotation increases and the $x$-ray beam becomes cone-shaped rather than fan-shaped. 